\title{
Retracted: Anti-GBM of Pregnancy: Acute Renal Failure Resolved after Spontaneous Abortion, Plasma Exchange, Hemodialysis, and Steroids
}

\author{
Case Reports in Nephrology \\ Received 23 February 2015; Accepted 23 February 2015 \\ Copyright (C) 2015 Case Reports in Nephrology. This is an open access article distributed under the Creative Commons Attribution \\ License, which permits unrestricted use, distribution, and reproduction in any medium, provided the original work is properly \\ cited.
}

The paper titled "Anti-GBM of Pregnancy: Acute Renal Failure Resolved after Spontaneous Abortion, Plasma Exchange, Hemodialysis, and Steroids" [1], published in Case Reports in Nephrology, has been retracted as it was submitted for publication without the knowledge and approval of all the other coauthors. Moreover, some of the conclusions were a bit overstated and there was additional data available that was not included in the published paper.

\section{References}

[1] M. M. Adnan, J. Morton, S. Hashmi, S. Abdul Mujeeb, W. Kern, and B. Cowley Jr., "Anti-GBM of pregnancy: acute renal failure resolved after spontaneous abortion, plasma exchange, hemodialysis, and steroids," Case Reports in Nephrology, vol. 2014, Article ID 243746, 4 pages, 2014. 